\title{
The Effects of Simultaneous Pulmonary Rehabilitation during Thoracic Radiotherapy in the Treatment of Malignant Diseases
}

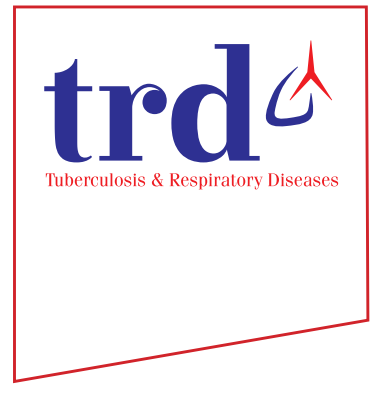

Myeong Geun Choi, M.D. ${ }^{1}{ }^{(i)}$, Hyang Yi Lee, B.P.T. ${ }^{1}$, Si Yeol Song, M.D., Ph.D. ${ }^{2}$, Su Ssan Kim, M.D., Ph.D. ${ }^{2}$, Seung Hak Lee, M.D., Ph.D. ${ }^{3}$, Won Kim, M.D., Ph.D. ${ }^{3}$, Chang-Min Choi, M.D., Ph.D. ${ }^{1,4}$ and Sei Won Lee, M.D., Ph.D. ${ }^{1}$ (10

Departments of ${ }^{1}$ Pulmonary and Critical Care Medicine, ${ }^{2}$ Radiation Oncology, ${ }^{3}$ Rehabilitation Medicine, and ${ }^{4}$ Oncology, Asan Medical Center, University of Ulsan College of Medicine, Seoul, Republic of Korea

Background: Radiotherapy is a common treatment option for lung or esophageal cancer, particularly when surgery is not feasible for patients with poor lung function. However, radiotherapy can affect pulmonary function and thereby induce pneumonitis or pneumonia, which can be fatal in patients with respiratory impairment. The purpose of this study is to evaluate if reductions in pulmonary function after radiotherapy can be minimized through simultaneous pulmonary rehabilitation (PR).

Methods: In this matched case control study, we retrospectively analyzed patients who had undergone radiotherapy for thoracic malignant disease between January 2018 and June 2019. We analyzed results from pulmonary function tests and 6-minute walking tests (6MWT) conducted within the six months before and after radiotherapy treatment.

Results: In total, results from 144 patients were analyzed, with 11 of the patients receiving PR and radiotherapy simultaneously. Of the 133 patients in the control group, 33 were matched with 11 patients in the PR group. Changes in forced expiratory volume in one second $\left(\mathrm{FEV}_{1}\right)$ and $\mathrm{FEV}_{1} /$ forced vital capacity were significantly different between the PR group and the matched control group $(240 \mathrm{~mL}$ vs. $-10 \mathrm{~mL}, \mathrm{p}=0.017$ and $5.5 \%$ vs. $1.0 \%$, $\mathrm{p}=0.038$, respectively). The median distance of 6MWT in the PR group also increased significantly, from $407.5 \mathrm{~m}$ to $493.0 \mathrm{~m}$ after radiotherapy $(\mathrm{p}=0.017)$.

Conclusion: Simultaneous PR improved pulmonary function, particularly in measures of $\mathrm{FEV}_{1}$, and exercise capacity for patients with lung or esophageal cancer even after radiotherapy treatment. These findings may provide an important base of knowledge for further large population studies with long-term follow-up analysis in the identification of the PR's effects during thoracic radiotherapy.

Keywords: Pulmonary Rehabilitation; Radiotherapy; Pulmonary Function Tests

Address for correspondence: Sei Won Lee, M.D., Ph.D.

Department of Pulmonary and Critical Care Medicine, Asan Medical Center, University of Ulsan College of Medicine, 88 Olympic-ro 43-gil, Songpa-gu, Seoul 05505, Republic of Korea

Phone: 82-2-3010-3990, Fax: 82-2-3010-6968, E-mail: iseiwon@gmail.com

Received: Nov. 8, 2020, Revised: Jan. 1, 2021, Accepted: Feb. 10, 2021, Published online: Feb. 10, 2021

@() It is identical to the Creative Commons Attribution Non-Commercial License (http://creativecommons.org/licenses/by-nc/4.0/). 


\section{Introduction}

Pulmonary rehabilitation (PR) is a broad, comprehensive treatment concept including exercise, education, and lifestyle modification. It improves both physiologic and psychologic condition by encouraging health-enhancing behaviors ${ }^{1}$. PR is an essential non-pharmacologic treatment, which can improve quality of life, symptoms, and pulmonary functions ${ }^{2}$.

The majority of evidence concerning PR focuses on chronic obstructive pulmonary disease (COPD); however, PR can also be performed for other respiratory diseases, such as interstitial lung disease, bronchiectasis, cystic fibrosis, asthma, pulmonary artery hypertension, lung cancer, and transplantation ${ }^{3}$. Lung cancer is often accompanied by COPD and/or interstitial lung disease, which can limit treatment and increase treatment-related complications ${ }^{4}$. PR has been suggested as means to minimize treatment-related complications. A previous randomized controlled trial for lung cancer has shown that preoperative PR can increase exercise capacity ${ }^{5}$, which is related to postoperative morbidity. In another study, PR was shown to significantly increase forced expiratory volume in one second $\left(\mathrm{FEV}_{1}\right)$ in lung cancer patients who undertook induction concurrent chemo-radiotherapy (CCRT), particularly among patients with respiratory impairment or history of smoking ${ }^{6}$.

Radiotherapy can be a treatment option in patients with thoracic malignancy, including lung and esophageal cancers. However, thoracic radiotherapy can affect pulmonary function especially with diminishing $\mathrm{FEV}_{1}$ and diffusing capacity for carbon monoxide (DLco). Moreover, it can also induce pneumonitis or pneumonia, which can be fatal in patients with respiratory impairment ${ }^{7-9}$. Although some studies exist regarding PR in patients with thoracic malignancy, most of those studies were on the effect of preoperative and postoperative PR. Conversely, no study exists concerning the effects of simultaneous PR during radiotherapy with the control group. The purpose of this study is to evaluate whether reduction in pulmonary function after radiotherapy can be minimized through simultaneous PR.

\section{Materials and Methods}

\section{Study design and patients}

This was a retrospective, matched case-control study. The inclusion criteria were as follows: patients $>19$ years who received thoracic radiotherapy for pathologically confirmed malignant diseases and underwent pulmonary function test (PFT) within 6 months before initiation and after the termination of radiotherapy. The 180 patients who met these inclusion criteria were divided into two groups, PR group and control

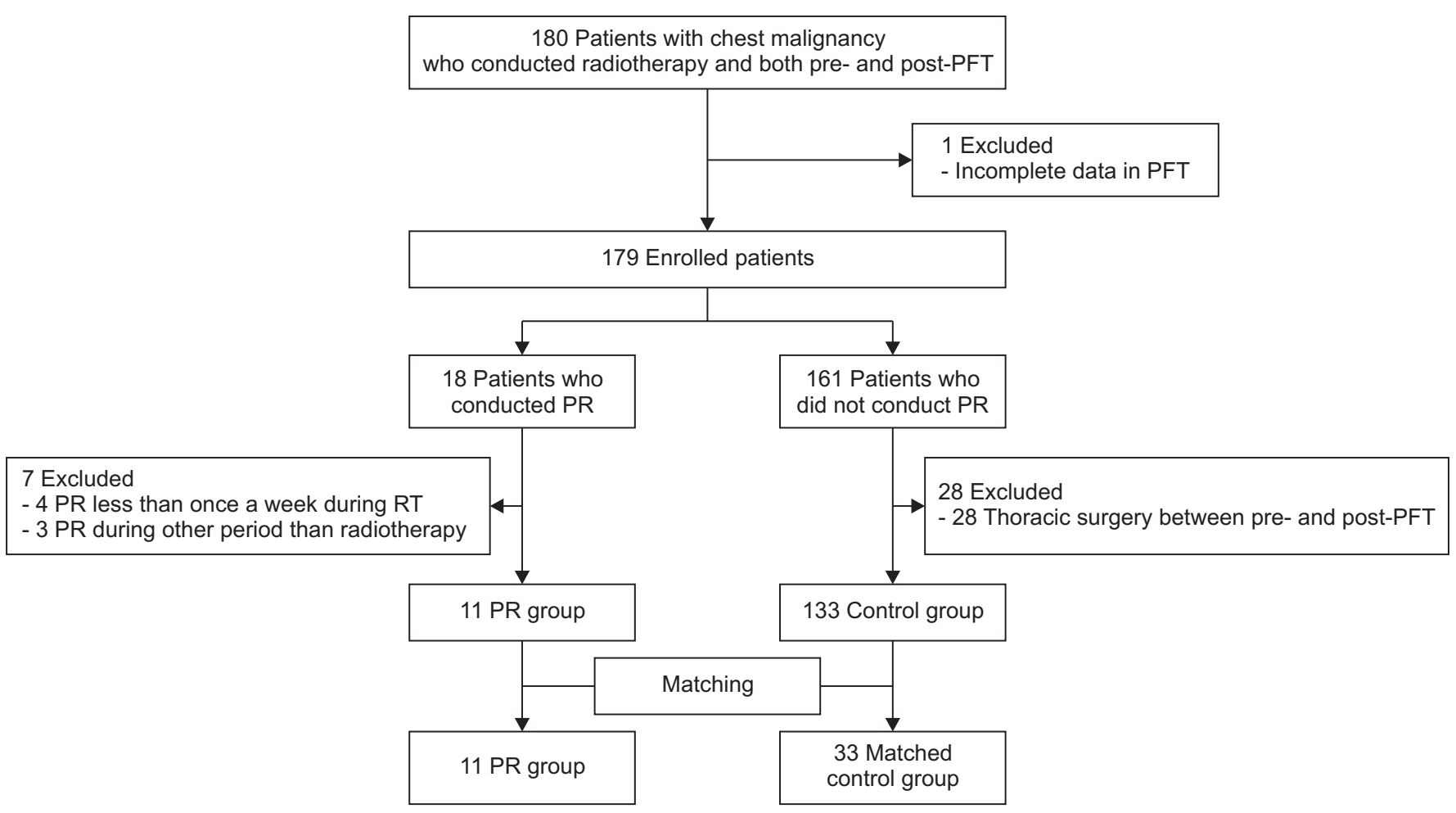

Figure 1. Consort flow diagram of the study. PFT: pulmonary function test; PR: pulmonary rehabilitation; RT: radiotherapy. 
Table 1. Baseline characteristics of patients

\begin{tabular}{|c|c|c|c|c|c|}
\hline & $\begin{array}{l}\text { PR group } \\
(n=11)\end{array}$ & $\begin{array}{l}\text { Matched control } \\
\text { group }(n=33)\end{array}$ & $\begin{array}{l}\text { All control group } \\
\qquad(n=133)\end{array}$ & $\begin{array}{c}\text { Total } \\
(\mathrm{n}=144)\end{array}$ & p-value* \\
\hline Age, median (IQR), yr & $68(10)$ & $67(9)$ & $66(12.5)$ & $66.5(12)$ & $0.789^{\dagger}$ \\
\hline Male sex & $11(100)$ & $33(100)$ & $113(85.0)$ & $124(86.1)$ & $\mathrm{N} / \mathrm{A}$ \\
\hline BMI, median (IQR), $\mathrm{kg} / \mathrm{m}^{2}$ & $22.73(3.69)$ & $23.98(6.46)$ & $24.05(5.52)$ & $24(5.28)$ & $0.196^{\dagger}$ \\
\hline Pathology & & & & & $0.617^{*}$ \\
\hline NSCLC & $10(90.9)$ & $26(78.8)$ & $91(68.4)$ & $101(70.1)$ & \\
\hline Adenocarcinoma & $2(18.2)$ & $16(48.5)$ & $40(30.1)$ & $42(29.2)$ & \\
\hline Squamous cell carcinoma & $5(45.5)$ & $10(30.3)$ & $42(31.6)$ & $47(32.6)$ & \\
\hline Others & $3(27.3)$ & $0(0)$ & $9(6.8)$ & $12(8.3)$ & \\
\hline SCLC & $0(0)$ & $4(12.1)$ & $16(12.0)$ & $16(11.1)$ & \\
\hline Esophageal cancer & $1(9.1)$ & $1(3.0)$ & $15(11.3)$ & $16(11.1)$ & \\
\hline Squamous cell carcinoma & $1(9.1)$ & $1(3.0)$ & $14(10.5)$ & $15(10.4)$ & \\
\hline Adenocarcinoma & $0(0)$ & $0(0)$ & $1(0.8)$ & $1(0.7)$ & \\
\hline Malignant thymoma & $0(0)$ & $1(3.0)$ & $2(1.5)$ & $2(1.4)$ & \\
\hline Others & $0(0)$ & $1(3.0)$ & $9(6.8)$ & $9(6.3)$ & \\
\hline ECOG performance status & & & & & $0.603^{\ddagger}$ \\
\hline $0-1$ & $10(90.9)$ & $30(90.9)$ & $113(85.0)$ & $123(85.4)$ & \\
\hline 2 & $1(9.1)$ & $2(6.1)$ & $18(13.5)$ & $19(13.2)$ & \\
\hline 3 & $0(0)$ & $1(3.0)$ & $2(1.5)$ & $2(1.4)$ & \\
\hline \multicolumn{6}{|l|}{ Stage } \\
\hline NSCLC & $10(90.9)$ & $26(78.8)$ & $91(68.4)$ & $101(70.1)$ & $0.432^{\ddagger}$ \\
\hline I & $3(27.3)$ & $12(36.4)$ & $29(21.8)$ & $32(22.2)$ & \\
\hline II & $2(18.2)$ & $4(12.1)$ & $12(9.0)$ & $14(9.7)$ & \\
\hline III & $3(27.3)$ & $9(27.3)$ & $43(32.3)$ & $46(31.9)$ & \\
\hline IV & $2(18.2)$ & $1(3.0)$ & $7(5.3)$ & $9(6.3)$ & \\
\hline SCLC & $0(0)$ & $4(12.1)$ & $16(12.0)$ & $16(11.1)$ & N/A \\
\hline Limited stage & $0(0)$ & $3(9.1)$ & $14(10.5)$ & $14(9.7)$ & \\
\hline Extensive stage & $0(0)$ & $1(3.0)$ & $2(1.5)$ & $2(1.4)$ & \\
\hline Esophageal cancer & $1(9.1)$ & $1(3.0)$ & $15(11.3)$ & $16(11.1)$ & $\mathrm{N} / \mathrm{A}$ \\
\hline I & $0(0)$ & $1(3.0)$ & $1(0.8)$ & $1(0.7)$ & \\
\hline II & $0(0)$ & $0(0)$ & $6(4.5)$ & $6(4.2)$ & \\
\hline III & $1(9.1)$ & $0(0)$ & $7(5.3)$ & $8(5.6)$ & \\
\hline IV & $0(0)$ & $0(0)$ & $1(0.8)$ & $1(0.7)$ & \\
\hline Smoking & & & & & $>0.99^{\dagger}$ \\
\hline Never & $0(0)$ & $2(6.1)$ & $26(19.5)$ & $26(18.1)$ & \\
\hline Former & $10(90.9)$ & $27(81.8)$ & $88(66.2)$ & $98(68.1)$ & \\
\hline Current & $1(9.1)$ & $4(12.1)$ & $18(13.5)$ & $19(13.2)$ & \\
\hline \multicolumn{6}{|l|}{ Underlying lung disease } \\
\hline COPD & $8(72.7)$ & $20(60.6)$ & $45(33.8)$ & $53(36.8)$ & $0.719^{\ddagger}$ \\
\hline Asthma & $1(9.1)$ & $1(3.0)$ & $7(5.3)$ & $8(5.6)$ & $0.442^{\dagger}$ \\
\hline ILD & $0(0)$ & $1(3.0)$ & $12(9.0)$ & $12(8.3)$ & $>0.99^{*}$ \\
\hline
\end{tabular}


Table 1. Continued

\begin{tabular}{|c|c|c|c|c|c|}
\hline & $\begin{array}{l}\text { PR group } \\
(n=11)\end{array}$ & $\begin{array}{l}\text { Matched control } \\
\text { group }(n=33)\end{array}$ & $\begin{array}{l}\text { All control group } \\
(n=133)\end{array}$ & $\begin{array}{c}\text { Total } \\
(n=144)\end{array}$ & p-value* \\
\hline Purpose of RT & & & & & $0.366^{*}$ \\
\hline Definitive & $11(100)$ & $20(60.6)$ & $77(57.9)$ & $88(61.1)$ & \\
\hline Palliative & $0(0)$ & $1(3.0)$ & $4(3.0)$ & $4(2.8)$ & \\
\hline Salvage & $0(0)$ & $4(12.1)$ & $18(13.5)$ & $18(12.5)$ & \\
\hline Preoperation & $0(0)$ & $2(6.1)$ & $15(11.3)$ & $15(10.4)$ & \\
\hline Postoperation & $0(0)$ & $6(18.2)$ & $18(13.5)$ & $18(12.5)$ & \\
\hline Others & $0(0)$ & $0(0)$ & $1(0.8)$ & $1(0.7)$ & \\
\hline PR duration, median (IQR), wk & $4(5)$ & N/A & N/A & $\mathrm{N} / \mathrm{A}$ & \\
\hline RT duration, median (IQR), day & $29(33)$ & $41(32.5)$ & $41(28.5)$ & $40.5(29.5)$ & $0.487^{\dagger}$ \\
\hline RT fraction, median (IQR), cGY & $6,000(400)$ & $6,000(745)$ & $5,600(1,000)$ & $5,775(1,000)$ & $0.689^{+}$ \\
\hline Analysis period, median (IQR) & $329(326)$ & $350(216)$ & $372(222)$ & $370(225)$ & $0.487^{\dagger}$ \\
\hline
\end{tabular}

Values are presented as number (\%) unless otherwise indicated.

*Comparison between PR group and matched control group. ${ }^{\dagger}$ Mann-Whitney test. ${ }^{*}$ Fisher exact test.

PR: pulmonary rehabilitation; IQR: interquartile range; BMI: body mass index; NSCLC: non-small cell lung cancer; SCLC: small cell lung cancer; ECOG: Eastern Cooperative Oncology Group; N/A: not available; COPD: chronic obstructive pulmonary disease; ILD: interstitial lung disease; RT: radiotherapy.

group, according to whether PR was performed or not. Patients were excluded if they received any treatment (e.g., lung resection or initiation of new inhalers) between pre- and postPFT that may affect study results. In addition, patients who received PR for less than once a week during radiotherapy or during the period when radiotherapy was not performed were also excluded. Finally, 11 patients performed PR simultaneously more than once a week during radiotherapy, and 133 patients received only radiotherapy. Of the 133 patients in the control group, 33 patients were matched in a 1:3 ratio with respect to age, sex, and baseline PFT with 11 patients in the PR group (Figure 1).

This study was approved by the institutional review board of the Asan Medical Center (IRB No. 2019-0905) and was conducted in accordance with the ethical standards of the Declaration of Helsinki. Requirement for written informed consent was waived by the review board.

\section{Pulmonary rehabilitation}

All 11 patients of the PR group received PR when visiting the medical center for radiotherapy more than once a week. The program included the following steps, which focused on supervised exercise (Supplementary Figure S1). First, we checked patient smoking status and provided smoking cessation education and nutritional counseling. If the patient used an inhaler, inhaler operation was confirmed, and any mistakes were corrected. Then, patients practiced abdominal breathing and pursed-lip breathing, inhaling through the nose and slowly exhaling with lips closed. Next, patients performed aerobic exercises such as walking and biking on treadmill to the degree assessed by 6-minute walking test (6MWT) or cardiopulmonary exercise test. The exercise was prescribed according to the frequency, intensity, time, and type principle based on their underlying disease and exercise capacity ${ }^{10}$. Patients then performed muscle exercises of the upper and lower extremities, stretching and relaxation. Patients with productive sputum were educated about proper expectoration methods, such as forced expiration huffing. They were encouraged to continue this exercise in their homes. All patients were required to fill out their exercise diary until next visit, with exercise intensity, duration and type being prescribed to maintain PR at home. The exercise prescription form and selfexercise diary are shown in Supplementary Table S1.

\section{Outcomes}

The primary outcome of this study was the change of PFT from baseline, including forced vital capacity (FVC), $\mathrm{FEV}_{1}$, $\mathrm{FEV}_{1} / \mathrm{FVC}$, and $\mathrm{DLco}^{11}$. Secondary outcomes were 6MWT, 6-month rate of pneumonia and radiation pneumonitis and 6-month overall survival. PFT results within 6 months before and after radiotherapy were analyzed and reported as baseline and post-PFT, respectively. Pneumonia and radiation pneumonitis were determined with chest computed tomography and chest X-ray images. Pneumonia was analyzed as an event when antibiotics were prescribed for pneumonia after referring to chest image and patient symptoms. Similarly, radiation pneumonitis was considered when steroids were prescribed for patient symptoms of grade 2 or higher, based on 
chest image evidence. Survival was analyzed for the full study period.

\section{Statistical analysis}

Demographic characteristics at baseline were compared between enrolled patients. Wilcoxon signed-rank test or Mann-Whitney U test was used to compare continuous variables. Fisher exact test was used to compare categorical variables. Control group was extracted by baseline age, sex, FVC $(\%)$, and $\mathrm{FEV}_{1}(\%)$ matching with the PR group at a ratio of 3:1. Time to pneumonia, time to radiation pneumonitis, or overall survival analyses were performed using Kaplan-Meier curve and log-rank test. A p-value of less than 0.05 was considered statistically significant. Statistical analyses were performed using IBM SPSS version 25.0 (IBM Corp., Armonk, NY, USA).

\section{Results}

\section{Patients}

From 144 total patients, 11 with simultaneous PR during radiotherapy were categorized as the PR group, and 33 were included as the matched control group. Patients in PR group underwent PR 1.5 times per week on average. Baseline characteristics were similar between the PR group and the matched control group (Table 1). Median age of all patients was 66.5 years ( 68 years for the PR group and 67 for the matched control group), and $124(86.1 \%)$ of all patients were male. All patients in both the PR and matched control group were male. Ten patients $(90.9 \%)$ in the PR group and $26(78.8 \%)$ in matched control group had non-small cell lung cancer (NSCLC). The Eastern Cooperative Oncology Group scale of performance status values for most patients were between 0 and 1 . No difference was observed between the two groups regarding NSCLC stage and smoking status. Regarding underlying lung disease, eight ( $72.7 \%)$ of the PR group and $20(60.6 \%)$ of the matched control group had COPD. Median fraction of radiotherapy was the same in the two groups $(6,000$ cGY). As baseline PFT was used for individual matching, FVC ( $76.0 \%$ vs. $79.0 \%)$ and $\mathrm{FEV}_{1}(57.0 \%$ vs. $59.0 \%)$ were similar between the two groups.

\section{Changes of PFT from baseline}

Change from baseline in $\mathrm{FEV}_{1}$ was significantly different between PR group and matched control group $(240 \mathrm{~mL}$ vs. -10 $\mathrm{mL}$, respectively, $\mathrm{p}=0.017$ ) (Figure 2 ). $\mathrm{FEV}_{1} / \mathrm{FVC}$ was found to increase significantly more in the PR group $(5.5 \%$ vs. $1.0 \%$, $\mathrm{p}=0.038)$. Changes from baseline in FVC (30 mL vs. $-50 \mathrm{~mL})$ and DLco (2.5\% vs. $-7.0 \%)$ were also greater in the PR group than matched control group; however, these differences were not statistically significant ( $\mathrm{p}=0.308$ and $\mathrm{p}=0.133$, respectively) (Figure 2).

\section{PFT, 6MWT, and safety in PR group}

Comparing pre- and post-PFT in the PR group, $\mathrm{FEV}_{1}(\mathrm{~L})$ and $\mathrm{FEV}_{1} / \mathrm{FVC}(\%)$ both increased significantly after PR dur-
A

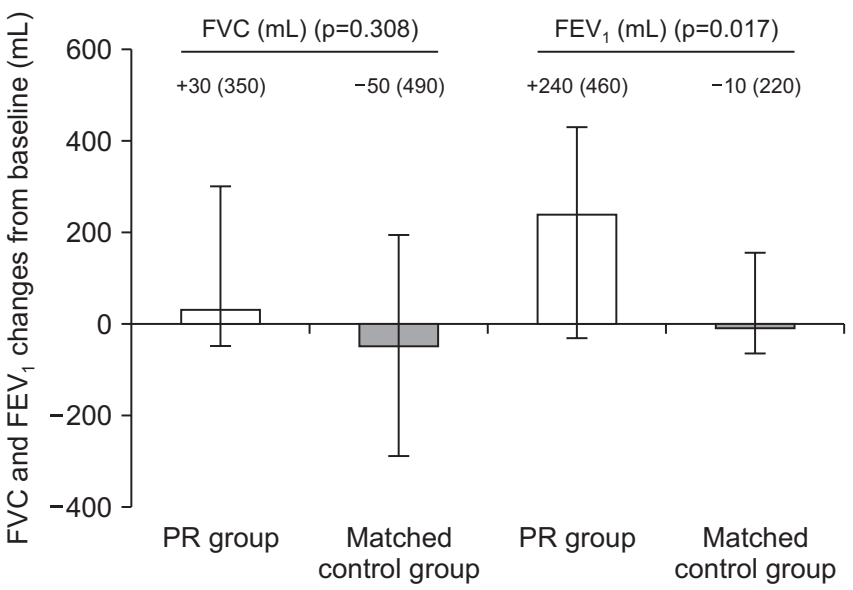

B

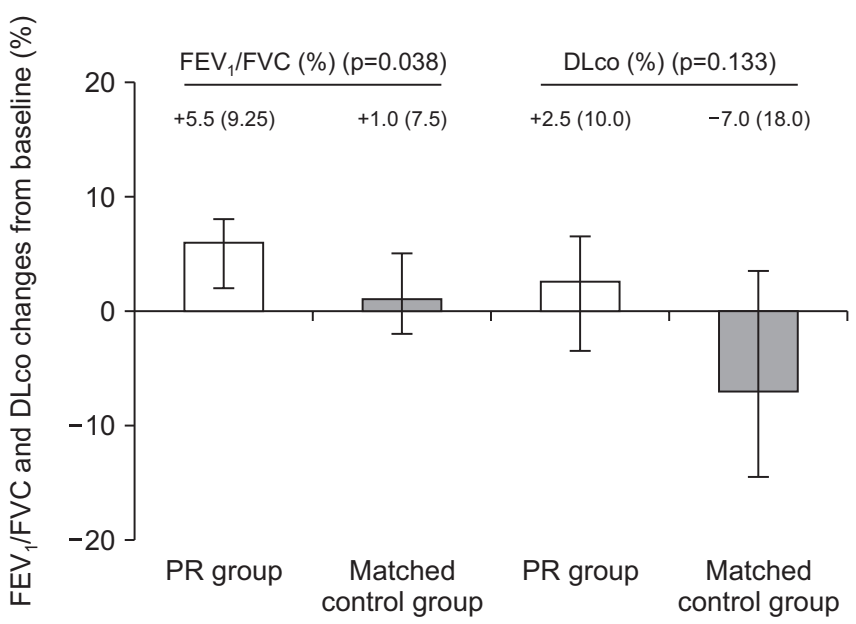

Figure 2. Changes from baseline in pulmonary function test. (A) The forced vital capacity (FVC, mL) change from baseline was greater than that of the pulmonary rehabilitation (PR) group $(+30 \mathrm{~mL}$ vs. $-50 \mathrm{~mL}, \mathrm{p}=0.308)$, and the forced expiratory volume in 1 second $\left(\mathrm{FEV}, \mathrm{mL}_{1}\right)$ change from baseline was significantly greater than that of the PR group $(+240 \mathrm{~mL}$ vs. $-10 \mathrm{~mL}, \mathrm{p}=0.017)$. (B) $\mathrm{FEV} / \mathrm{FVC}(\%)$ increased more in the PR group ( $+5.5 \%$ vs. $+1.0 \%, \mathrm{p}=0.038$ ), and the diffusing capacity for carbon monoxide (DLco, \%) change from baseline was greater in the PR group ( $+2.5 \%$ vs. $-7.0 \%$, $\mathrm{p}=0.133)$; Error bars represent the interquartile ranges (IQR) of the median. The text above each column indicates the median (IQR). 
ing radiotherapy ( $\mathrm{p}=0.023$ and $\mathrm{p}=0.012$, respectively). Median distance of 6MWT also significantly increased from $407.5 \mathrm{~m}$ to $493.0 \mathrm{~m}$ after PR during radiotherapy ( $\mathrm{p}=0.017$ ). No significant differences were observed in FVC (L) or DLco (\%). In the matched control group, no significant differences were observed between pre- and post-PFT values in any of these parameters (Table 2). No adverse events related to PR, such as musculoskeletal complications, extreme fatigue, dizziness or cardiac instability, were observed in PR group during the analysis period.

\section{Sensitivity analysis}

In 53 patients with COPD from the total patients, median changes in PFT and 6MWT from baseline improved more in patients who received PR during radiotherapy $(n=8)$ than in those who did not PR ( $\mathrm{n}=45)$, although this was not statistically significant $\left(\mathrm{FEV}_{1}, 240 \mathrm{~mL}\right.$ vs. $50 \mathrm{~mL}$; $\mathrm{p}=0.075$ and 6MWT, 93 $\mathrm{m}$ vs. $-10 \mathrm{~m} ; \mathrm{p}=0.097$ ). In 100 patients with NSCLC, median changes in $\mathrm{FEV}_{1}$ and 6MWT from baseline also improved significantly more in patients who received $\mathrm{PR}(\mathrm{n}=10)$ than in those who did not $(\mathrm{n}=90)\left(\mathrm{FEV}_{1}, 250 \mathrm{~mL}\right.$ vs. $-10 \mathrm{~mL} ; \mathrm{p}=0.023$ and 6MWT, $93 \mathrm{~m}$ vs. $-30 \mathrm{~m} ; \mathrm{p}=0.017$ ). Among 107 patients receiving conventional radiotherapy, median changes in $\mathrm{FEV}_{1}$ and 6MWT from baseline were also greater in those who received PR (n=6) than in those who did not $(n=101)$, although 6MWT changes did not reach statistical significance $\left(\mathrm{FEV}_{1}, 270\right.$ $\mathrm{mL}$ vs. $-10 \mathrm{~mL} ; \mathrm{p}=0.023$ and $\mathrm{p}=0.036$, respectively) (Table 3 ).

\section{Radiation pneumonitis, pneumonia, and survival}

The occurrences of radiation pneumonitis $\geq$ grade 2 were

Table 2. Pulmonary function test before and after radiotherapy according to simultaneous pulmonary rehabilitation

\begin{tabular}{|c|c|c|c|c|c|c|}
\hline & \multicolumn{3}{|c|}{ PR group $(n=11)$} & \multicolumn{3}{|c|}{ Matched control group $(n=33)$} \\
\hline & Pre & Post & p-value* & Pre & Post & p-value* \\
\hline FVC, $\%$ & & & 0.196 & & & 0.281 \\
\hline Mean \pm SD & $80.64 \pm 11.02$ & $84.27 \pm 8.80$ & & $79.27 \pm 10.56$ & $76.15 \pm 13.97$ & \\
\hline Median (IQR) & $76.0(15.0)$ & $82.0(13.0)$ & & $79.0(12.0)$ & $76.0(18.5)$ & \\
\hline FVC, L & & & 0.563 & & & 0.386 \\
\hline Mean \pm SD & $3.45 \pm 0.51$ & $3.57 \pm 0.43$ & & $3.40 \pm 0.52$ & $3.29 \pm 0.68$ & \\
\hline Median (IQR) & $3.42(0.70)$ & $3.39(0.78)$ & & $3.36(0.64)$ & $3.28(0.98)$ & \\
\hline $\mathrm{FEV}_{1}, \%$ & & & 0.011 & & & 0.474 \\
\hline Mean \pm SD & $53.55 \pm 14.00$ & $62.82 \pm 15.74$ & & $57.30 \pm 13.17$ & $58.00 \pm 15.88$ & \\
\hline Median (IQR) & $57.0(26.0)$ & $68.0(27.0)$ & & $59.0(20.5)$ & $58.0(25.0)$ & \\
\hline $\mathrm{FEV}_{1}, \mathrm{~L}$ & & & 0.023 & & & 0.681 \\
\hline Mean \pm SD & $1.66 \pm 0.50$ & $1.93 \pm 0.58$ & & $1.75 \pm 0.48$ & $1.77 \pm 0.55$ & \\
\hline Median (IQR) & $1.71(0.89)$ & $2.11(0.92)$ & & $1.70(0.77)$ & $1.81(0.91)$ & \\
\hline $\mathrm{FEV}_{1} / \mathrm{FVC}, \%$ & & & 0.012 & & & 0.085 \\
\hline Mean \pm SD & $48.00 \pm 12.98$ & $54.46 \pm 15.44$ & & $51.94 \pm 13.76$ & $53.76 \pm 12.93$ & \\
\hline Median (IQR) & $51.0(23.0)$ & $58.0(30.0)$ & & $54.0(23.0)$ & $55.0(20.5)$ & \\
\hline DLco, $\mathrm{mL} / \mathrm{mm} \mathrm{Hg} / \mathrm{min}$ & & & 0.759 & & & 0.110 \\
\hline Mean \pm SD & $12.15 \pm 4.03$ & $12.28 \pm 4.14$ & & $13.22 \pm 3.87$ & $11.92 \pm 3.85$ & \\
\hline Median (IQR) & $10.75(5.40)$ & $11.35(5.78)$ & & $12.00(7.25)$ & $12.90(5.45)$ & \\
\hline DLco, $\%$ & & & 0.444 & & & 0.123 \\
\hline Mean \pm SD & $58.60 \pm 16.97$ & $60.00 \pm 16.08$ & & $61.78 \pm 18.67$ & $56.67 \pm 18.59$ & \\
\hline Median (IQR) & $57.5(25.3)$ & $56.5(29.3)$ & & $64.0(35.0)$ & $66.0(28.0)$ & \\
\hline 6MWT, m & & & 0.017 & & & - \\
\hline Mean \pm SD & $419.9 \pm 89.9$ & $478.3 \pm 62.4$ & & - & - & \\
\hline Median (IQR) & $407.5(116.3)$ & $493.0(80.5)$ & & - & - & \\
\hline
\end{tabular}

*Wilcoxon signed-rank test.

PR: pulmonary rehabilitation; FVC: forced vital capacity; SD: standard deviation; IQR: interquartile range; $\mathrm{FEV}_{1}$ : forced vital capacity in one second; $\mathrm{DL}_{\mathrm{CO}}$ : diffusing capacity for carbon monoxide; $6 \mathrm{MWT}$ : 6-minute walking test. 
Table 3. Subgroup analysis of median changes in PFT

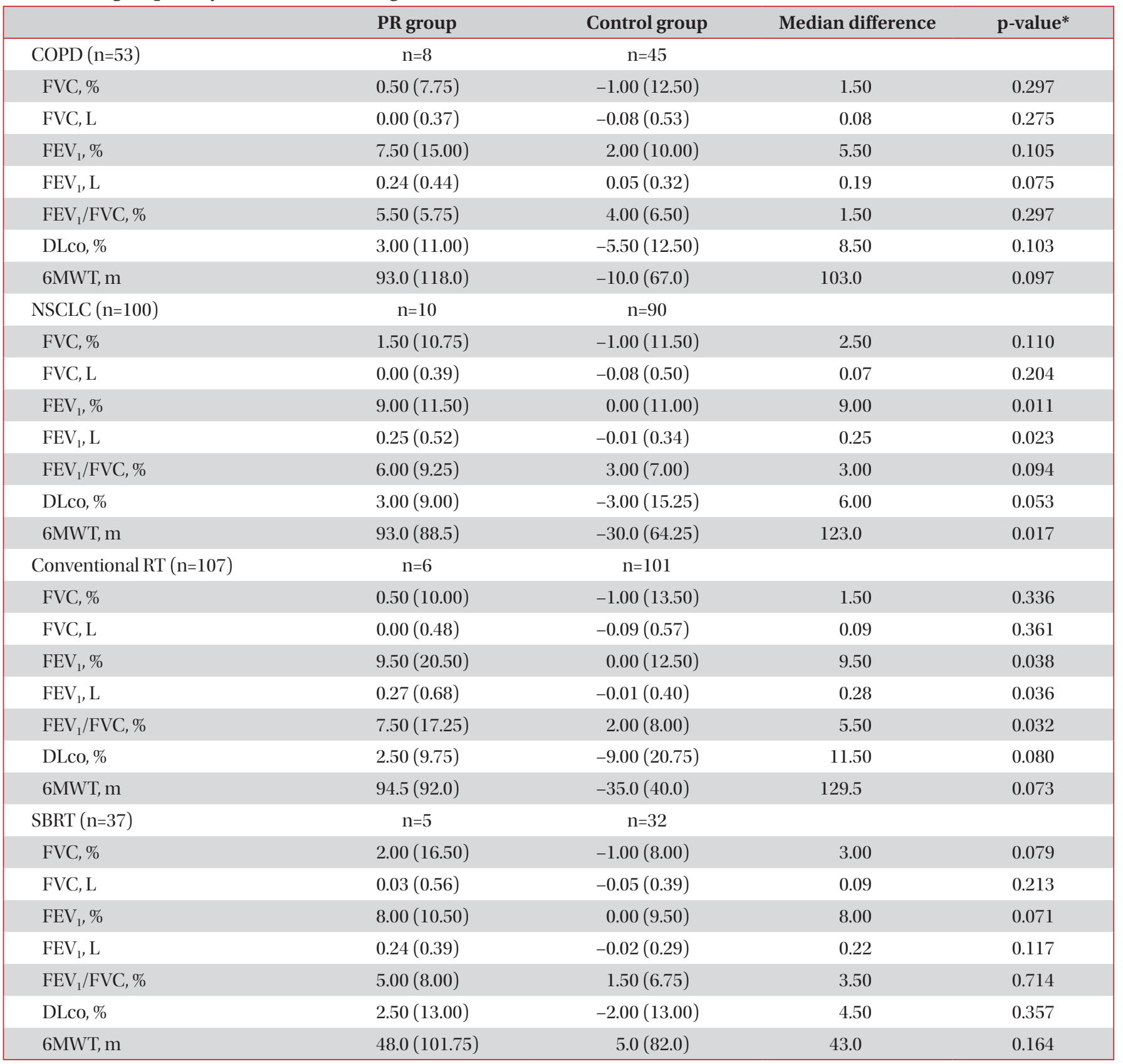

Values are presented as median (interquartile range).

*Mann-Whitney test.

PFT: pulmonary function test; PR: pulmonary rehabilitation; COPD: chronic obstructive pulmonary disease; FVC: forced vital capacity; FEV : forced vital capacity in one second; $\mathrm{DL}_{\mathrm{CO}}$ : diffusing capacity for carbon monoxide; 6MWT: 6-minute walking test; NSCLC: non-small cell lung cancer; RT: radiotherapy; SBRT: stereotactic body radiation therapy.

one $(9.1 \%)$ and four $(12.1 \%)$ in the PR and matched control group, respectively $(\mathrm{p}=0.789)$. The 6 -month incidence of radiation pneumonitis was 0 in the PR group and 0.124 in the matched control group (Figure 3A). Four (36.4\%) and nine $(27.3 \%)$ cases of pneumonia were observed in the PR and matched control group respectively during the analysis period $(\mathrm{p}=0.406)$. The median time to first pneumonia was 365 days for the PR group and could not be evaluated due to limited events in the matched control group. The 6-month incidence of pneumonia was 0.182 in the PR group and 0.216 

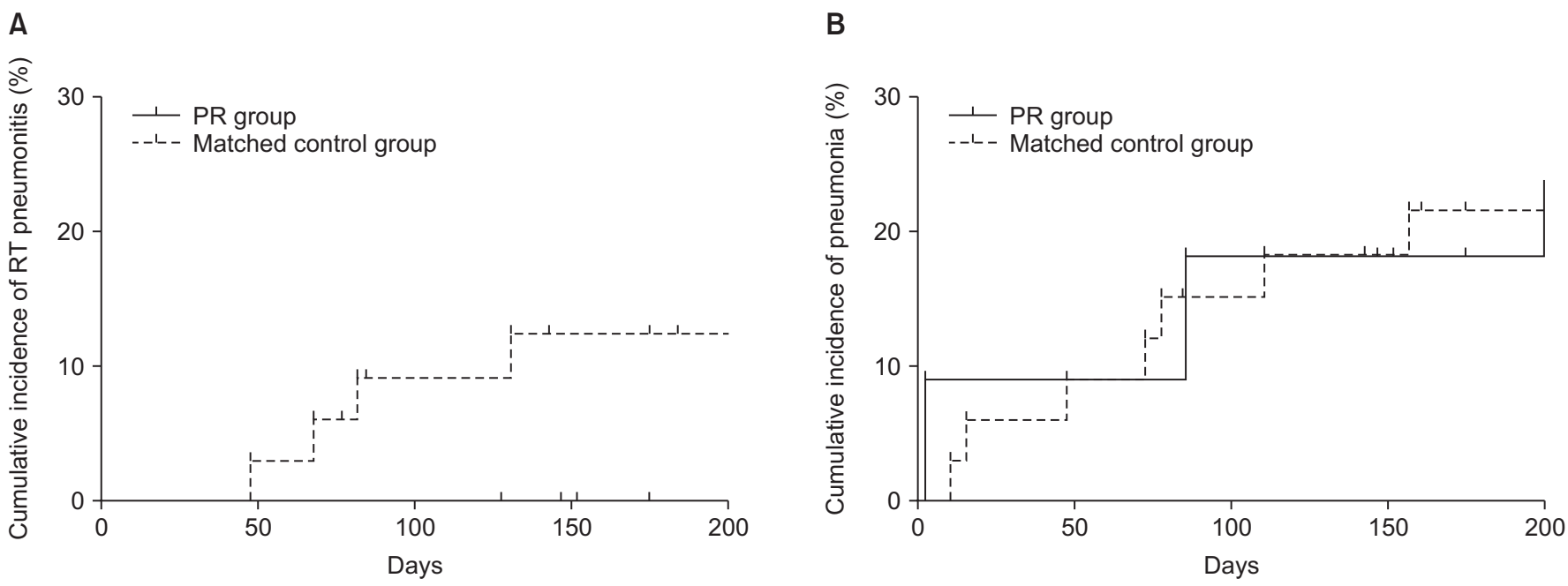

Figure 3. Kaplan-Meier curves. (A) Cumulative incidence of pneumonia ( $\mathrm{p}=0.406$ for log-rank test). (B) Cumulative incidence of radiotherapy pneumonitis ( $\mathrm{p}=0.789$ for log-rank test). PR: pulmonary rehabilitation; RT: radiation.

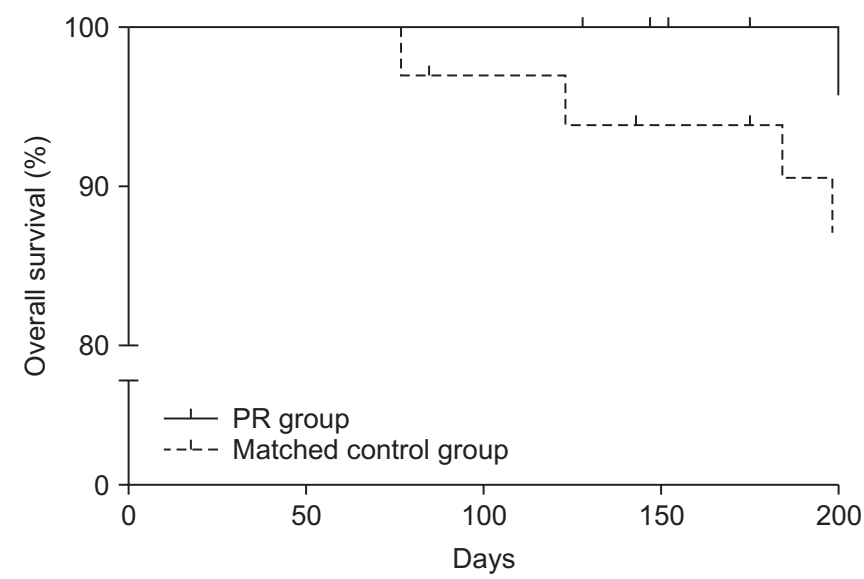

Figure 4. Kaplan-Meier curves. Overall survival ( $\mathrm{p}=0.662$ for $\log$ rank test). PR: pulmonary rehabilitation.

in the matched control group (Figure 3B). One death (9.1\%) and seven deaths (14.2\%) were recorded in the PR group and matched control group, respectively, during the analysis period. The 6-month survival rate was 1.0 in the PR group and 0.938 in the matched control group; however, no difference was observed between the groups in terms of overall survival based on Kaplan-Meier survival analysis ( $\mathrm{p}=0.662)$ (Figure 4).

\section{Discussion}

This study has showed several benefits of simultaneous PR during thoracic radiotherapy. All parameters of pulmonary function and exercise capacity improved despite radiotherapy, as combined PR, and $\mathrm{FEV}_{1}, \mathrm{FEV}_{1} / \mathrm{FVC}$, and $6 \mathrm{MWT}$ showed significant improvement. Meanwhile, pulmonary function, including $\mathrm{FEV}_{1}, \mathrm{FVC}$, and $\mathrm{DL}_{\mathrm{CO}}$ did not change or decreased after radiotherapy without $\mathrm{PR}$, although statistically not significant. Accordingly, $\mathrm{FEV}_{1}$ and $\mathrm{FEV}_{1} / \mathrm{FVC}$ improved significantly in the PR group, compared with matched control. No adverse events related to PR were noted. Thus, these results suggest that simultaneous PR is a safe and effective treatment during radiotherapy, which could be an option for patients with poor lung function. As far as we know, this study was the first to confirm the effects of simultaneous PR during thoracic radiotherapy.

Most studies regarding PR in lung cancer patients have been conducted in preoperative or postoperative conditions ${ }^{5,12-14}$. For radiotherapy, one previous study on PR for patients with CCRT demonstrated that PR significantly increases pulmonary function, particularly $\mathrm{FEV}_{1}$, in smokers and those with respiratory impairment; however, this study included a single arm without a control group ${ }^{6}$. Similar results were observed in our study. By comparing with a matched control, our study has provided more confirmative results that simultaneous PR can improve clinical performance after radiotherapy.

Among the changes of PFT from baseline, FEV $_{1}$ was most prominent in the PR group. $\mathrm{FEV}_{1}$ generally decreases after radiotherapy ${ }^{7}$; however, our study showed that $\mathrm{FEV}_{1}$ actually significantly increased in the PR group. This suggests that simultaneous PR can attenuate potential declines in lung function associated with radiotherapy, especially in $\mathrm{FEV}_{1}$. There are a few possible explanations for this. First, patients with COPD may have lung hyperinflation, and radiotherapy might reduce this $^{15,16}$. Simultaneous PR may additionally minimize the reduction of $\mathrm{FVC}$, providing a synergistic effect, ${ }^{6,17,18}$. Second, increased regular physical activity through PR may delay $\mathrm{FEV}_{1}$ decline related with radiotherapy. It is known that $\mathrm{FEV}_{1}$ is 
higher in patients with high physical activity ${ }^{19}$. Third, the comprehensive approach of PR may improve patients' daily life. Smoking cessation and inhaler education were also included in PR, alongside correction of inhaler technique. Accurate use of inhalers in patients with obstructive airway disease is very important ${ }^{20,21}$. This may be associated with acute exacerbation and prognosis ${ }^{22}$. Combined personalized and comprehensive PR approach may improve lung function beyond physical capacity. This benefit has been documented in another previous study ${ }^{23}$.

Median distance of 6MWT increased significantly from $407.5 \mathrm{~m}$ to $493.0 \mathrm{~m}$ in the PR group. Similar to a previous study about postoperative $\mathrm{PR}^{5}$, simultaneous $\mathrm{PR}$ also presented benefits in exercise capacity. In subgroup analysis including COPD, NSCLC, or types of radiotherapy, the results were also similar; however, they did not reach statistical significance due to small sample number.

PR protocol in this study was conducted in accordance with international guideline ${ }^{1}$. Center-based PR is usually considered as the standard with the greatest available evidence ${ }^{24}$. However, adherence is a concern in center-based PR, with transportation issue being one of the reasons ${ }^{25-28}$. Simultaneous PR in our study was relatively free from such issues. In the present study, patients visited the center for radiotherapy and could undertake PR during the same visit. To enhance benefits, patients were encouraged to continue PR at home as they were educated and prescribed.

To determine the effects of PR on survival in advanced cancer is challenging because of the progressive nature of the disease and relatively short life expectancy. In this study, 6-month survival rate was slightly higher in PR group (100\%) than matched control group (93.8\%); however, no significant difference was observed in overall survival during analysis period, which was similar to findings from other studies ${ }^{29-31}$. Early mortality rate may be lowered slightly in the PR group; however, PR alone was unable to change the natural course of the underlying disease in the long term.

There were some limitations in this study. First, this was a retrospective study with a relatively small sample size. PR during radiotherapy was considered as novel but with not enough evidence. Therefore, PR in this setting was not commonly prescribed. Despite the small number of patients, this study confirmed the possibility that PR can minimize the reduction of pulmonary function and improve exercise capacity during radiotherapy. Based on these preliminary results, prospective controlled studies can be performed for more confirmative results that have not been studied yet. Second, the underlying types of cancer and lung diseases were not homogenous, although the majority were lung cancer and COPD. Therefore, the application of these results in clinical practice may be limited. To overcome this limitation, age, sex, and pulmonary function were matched and radiation doses between the two groups were same $\mathrm{e}^{32}$. We should also consider that PR usually has minimal risk and the effects of exercise and activity were well proven in the general population ${ }^{33}$. If baseline characteristics, including an underlying lung disease, type and stage of cancer, purpose of radiotherapy, and radiation dose, are controlled in further studies, meaningful results can be obtained. Third, the proportion of males in this study was relatively high. In South Korea, lung cancer (70.1\%) and esophageal cancer (90.1\%) incidence are also much higher in males ${ }^{34}$, which affected the distribution in our study group (86.1\%). Finally, the retrospective nature of the study meant it was difficult to analyze symptoms and quality of life. This needs to be evaluated using an objective scale, such as modified medical research council dyspnea scale or COPD assessment test.

In conclusion, simultaneous PR improved pulmonary function, especially $\mathrm{FEV}_{1}$, and exercise capacity without adverse events in patients who underwent thoracic radiotherapy. Simultaneous PR could be performed at the hospital visit for radiotherapy, which may improve treatment adherence. With further studies based on this result, PR can be recommended as a non-pharmacological therapeutic option in patients receiving thoracic radiotherapy.

\section{Authors' Contributions}

Conceptualization: Lee SW. Methodology: Song SY, Kim SS, Lee SH, Kim W, Choi CM, Lee SW. Formal analysis: Choi MG, Lee HY, Lee SW. Data curation: Choi MG, Lee HY, Lee SW. Software: Choi MG, Lee HY. Validation: Choi MG, Song SY, Kim SS, Lee SH, Kim W, Choi CM, Lee SW. Investigation: Choi MG, Song SY, Kim SS, Lee SH, Kim W, Choi CM, Lee SW. Writing - original draft preparation: Choi MG. Writing - review and editing: Song SY, Kim SS, Lee SH, Kim W, Choi CM, Lee SW. Approval of final manuscript: all authors.

\section{Conflicts of Interest}

No potential conflict of interest relevant to this article was reported.

\section{Acknowledgments}

The authors would like to thank Enago (http://www.enago. co.kr) for the English language review.

\section{Funding}

This study was supported by grants (2018IT0964 and 2020IE0003) from the Asan Institute for Life Sciences, Asan Medical Center, Seoul, Korea. 


\section{Supplementary Material}

Supplementary material can be found in the journal homepage (http://www.e-trd.org).

Supplementary Table S1. The form of exercise prescription and exercise diary.

Supplementary Figure S1. Pulmonary rehabilitation protocol schematic diagram.

\section{References}

1. Rochester CL, Vogiatzis I, Holland AE, Lareau SC, Marciniuk DD, Puhan MA, et al. An Official American Thoracic Society/ European Respiratory Society policy statement: enhancing implementation, use, and delivery of pulmonary rehabilitation. Am J Respir Crit Care Med 2015;192:1373-86.

2. Troosters T, Casaburi R, Gosselink R, Decramer M. Pulmonary rehabilitation in chronic obstructive pulmonary disease. Am J Respir Crit Care Med 2005;172:19-38.

3. Spruit MA, Singh SJ, Garvey C, ZuWallack R, Nici L, Rochester C, et al. An official American Thoracic Society/European Respiratory Society statement: key concepts and advances in pulmonary rehabilitation. Am J Respir Crit Care Med 2013;188:e13-64.

4. de Torres JP, Marin JM, Casanova C, Cote C, Carrizo S, Cordoba-Lanus E, et al. Lung cancer in patients with chronic obstructive pulmonary disease: incidence and predicting factors. Am J Respir Crit Care Med 2011;184:913-9.

5. Stigt JA, Uil SM, van Riesen SJ, Simons FJ, Denekamp M, Shahin GM, et al. A randomized controlled trial of postthoracotomy pulmonary rehabilitation in patients with resectable lung cancer. J Thorac Oncol 2013;8:214-21.

6. Tarumi S, Yokomise H, Gotoh M, Kasai Y, Matsuura N, Chang SS, et al. Pulmonary rehabilitation during induction chemoradiotherapy for lung cancer improves pulmonary function. J Thorac Cardiovasc Surg 2015;149:569-73.

7. Niezink AG, de Jong RA, Muijs CT, Langendijk JA, Widder J. Pulmonary function changes after radiotherapy for lung or esophageal cancer: a systematic review focusing on dosevolume parameters. Oncologist 2017;22:1257-64.

8. Erven K, Weltens C, Nackaerts K, Fieuws S, Decramer M, Lievens Y. Changes in pulmonary function up to 10 years after locoregional breast irradiation. Int J Radiat Oncol Biol Phys 2012;82:701-7.

9. Pinnix CC, Smith GL, Milgrom S, Osborne EM, Reddy JP, Akhtari M, et al. Predictors of radiation pneumonitis in patients receiving intensity modulated radiation therapy for Hodgkin and non-Hodgkin lymphoma. Int J Radiat Oncol Biol Phys 2015;92:175-82.

10. Amercian Collge of Sports Medicine. ACSM's guidelines for exercise testing and prescription. 9th ed. Philadelphia: Lippincott Williams \& Wilkins; 2013.
11. Graham BL, Steenbruggen I, Miller MR, Barjaktarevic IZ, Cooper BG, Hall GL, et al. Standardization of spirometry 2019 update. An Official American Thoracic Society and European Respiratory Society technical statement. Am J Respir Crit Care Med 2019;200:e70-e88.

12. Nagarajan K, Bennett A, Agostini P, Naidu B. Is preoperative physiotherapy/pulmonary rehabilitation beneficial in lung resection patients? Interact Cardiovasc Thorac Surg 2011;13:300-2.

13. Cesario A, Ferri L, Galetta D, Cardaci V, Biscione G, Pasqua F, et al. Pre-operative pulmonary rehabilitation and surgery for lung cancer. Lung Cancer 2007;57:118-9.

14. Bobbio A, Chetta A, Ampollini L, Primomo GL, Internullo E, Carbognani $\mathrm{P}$, et al. Preoperative pulmonary rehabilitation in patients undergoing lung resection for non-small cell lung cancer. Eur J Cardiothorac Surg 2008;33:95-8.

15. O'Meara P, Guenette JA, Raghavan N, Amornputtisathaporn N, Demetz CE, Nolan RL, et al. Mechanisms of dyspnoea relief following radiation treatment in a patient with severe COPD. Eur Respir J 2011;38:728-30.

16. Yoshimi K, Ueki J, Seyama K, Takizawa M, Yamaguchi S, Kitahara E, et al. Pulmonary rehabilitation program including respiratory conditioning for chronic obstructive pulmonary disease (COPD): improved hyperinflation and expiratory flow during tidal breathing. J Thorac Dis 2012;4:259-64.

17. Stav D, Raz M, Shpirer I. Three years of pulmonary rehabilitation: inhibit the decline in airflow obstruction, improves exercise endurance time, and body-mass index, in chronic obstructive pulmonary disease. BMC Pulm Med 2009;9:26.

18. Embarak S, Mansour W, Mortada MA. Pulmonary rehabilitation slows the decline in forced expiratory volume in 1 second and improves body mass index in patients with chronic obstructive pulmonary disease. Egypt J Chest Dis Tuberc 2015;64:41-5.

19. Cheng YJ, Macera CA, Addy CL, Sy FS, Wieland D, Blair SN. Effects of physical activity on exercise tests and respiratory function. Br J Sports Med 2003;37:521-8.

20. Price DB, Roman-Rodriguez M, McQueen RB, BosnicAnticevich S, Carter V, Gruffydd-Jones K, et al. Inhaler errors in the CRITIKAL study: type, frequency, and association with asthma outcomes. J Allergy Clin Immunol Pract 2017;5:107181.

21. Dudvarski Ilic A, Zugic V, Zvezdin B, Kopitovic I, Cekerevac I, Cupurdija V, et al. Influence of inhaler technique on asthma and COPD control: a multicenter experience. Int J Chron Obstruct Pulmon Dis 2016;11:2509-17.

22. Lorx A, Czovek D, Gingl Z, Makan G, Radics B, Bartusek D, et al. Airway dynamics in COPD patients by within-breath impedance tracking: effects of continuous positive airway pressure. Eur Respir J 2017;49:1601270.

23. Incorvaia C, Russo A, Foresi A, Berra D, Elia R, Passalacqua G, et al. Effects of pulmonary rehabilitation on lung function in chronic obstructive pulmonary disease: the FIRST study. Eur 
J Phys Rehabil Med 2014;50:419-26.

24. Spruit MA, Pitta F, Garvey C, ZuWallack RL, Roberts CM, Collins EG, et al. Differences in content and organisational aspects of pulmonary rehabilitation programmes. Eur Respir J 2014;43:1326-37.

25. Sahin H, Naz I. Why are COPD patients unable to complete the outpatient pulmonary rehabilitation program? Chron Respir Dis 2018;15:411-8.

26. Mendes de Oliveira JC, Studart Leitao Filho FS, Malosa Sampaio LM, Negrinho de Oliveira AC, Hirata RP, Costa D, et al. Outpatient vs. home-based pulmonary rehabilitation in COPD: a randomized controlled trial. Multidiscip Respir Med 2010;5:401-8.

27. Keating A, Lee A, Holland AE. What prevents people with chronic obstructive pulmonary disease from attending pulmonary rehabilitation? A systematic review. Chron Respir Dis 2011;8:89-99.

28. Quist M, Rorth M, Langer S, Jones LW, Laursen JH, Pappot H, et al. Safety and feasibility of a combined exercise intervention for inoperable lung cancer patients undergoing chemotherapy: a pilot study. Lung Cancer 2012;75:203-8.
29. Licker M, Karenovics W, Diaper J, Fresard I, Triponez F, Ellenberger $\mathrm{C}$, et al. Short-term preoperative high-intensity interval training in patients awaiting lung cancer surgery: a randomized controlled trial. J Thorac Oncol 2017;12:323-33.

30. Baldwin C, Spiro A, Ahern R, Emery PW. Oral nutritional interventions in malnourished patients with cancer: a systematic review and meta-analysis. J Natl Cancer Inst 2012;104:37185.

31. Granger CL. Physiotherapy management of lung cancer. J Physiother 2016;62:60-7.

32. Marks LB, Bentzen SM, Deasy JO, Kong FM, Bradley JD, Vogelius IS, et al. Radiation dose-volume effects in the lung. Int J Radiat Oncol Biol Phys 2010;76(3 Suppl):S70-6.

33. Manini TM, Everhart JE, Patel KV, Schoeller DA, Colbert LH, Visser M, et al. Daily activity energy expenditure and mortality among older adults. JAMA 2006;296:171-9.

34. Jung KW, Won YJ, Kong HJ, Lee ES; Community of Population-Based Regional Cancer Registries. Cancer statistics in Korea: incidence, mortality, survival, and prevalence in 2015. Cancer Res Treat 2018;50:303-16 